\title{
Spontaneous solid-state foaming of nanocrystalline thermoelectric compounds at elevated temperatures
}

\author{
Samuel A. Humphry-Baker ${ }^{\mathrm{a}, \mathrm{b}^{*}}$ and Christopher A. Schuh ${ }^{\mathrm{a}}$ \\ ${ }^{\mathrm{a}}$ Department of Materials Science and Engineering, Massachusetts Institute of \\ Technology, Cambridge, MA 02139, USA \\ ${ }^{\mathrm{b}}$ Department of Materials, Imperial College, London SW7 2AZ, UK
}

*Corresponding author email: $\underline{\text { shumphry@ic.ac.uk }}$

\begin{abstract}
Nanocrystalline thermoelectric materials have improved properties, but are difficult to process to full density. During routine thermal processing operations such as powder consolidation and annealing, such compounds can spontaneously form pores, thus degrading their thermoelectric and mechanical properties. We systematically investigate pore formation during heat treatment of cold-pressed compacts of nanocrystalline $\mathrm{Bi}_{2} \mathrm{Te}_{3}$, combining dilatometry and electron microscopy to quantify pore morphology and the rate of pore growth. Pores are found to nucleate on Te-rich precipitates, which are ultimately attributable to a non-equilibrium solubility shift associated with defects in the nanostructured compound, and they grow by diffusional creep under the driving force of Te vapor pressure. This mechanistic insight reveals that, ironically, the same nonequilibrium processing and nanostructure desirable for improved thermoelectric performance also encourage foaming and challenge the formation of stable high density material. With an improved mechanistic understanding, however, we are also able to suggest strategies for improved materials design and processing.
\end{abstract}

\section{Keywords}

Thermoelectric; Nanostructures; Porosity; Bismuth telluride; Thermal stability; Powder processing 


\section{Introduction}

Bismuth telluride $\left(\mathrm{Bi}_{2} \mathrm{Te}_{3}\right)$ and its associated compounds are the best-known thermoelectric materials for low temperature applications. Their performance can be further improved by nanostructuring of the grain size [1-3], due to a reduction in thermal conductivity from interfacial scattering of phonons. Grain refinement, however, renders these materials unstable during subsequent thermal annealing: In addition to conventional grain growth [4], porosity has been reported to evolve in $\mathrm{Bi}_{2} \mathrm{Te}_{3}$ as well as other chalcogenide compounds during various powder processing operations such as pressureless [5-7], and pressure-assisted [8,9], sintering. Alternatively, pores can form during subsequent annealing of fully dense samples, for example in flash-evaporated thin films [10], or hot-pressed compounds [11-13]. Table 1 summarizes some of the literature data on pore formation in chalcogenide thermoelectric compounds. What is common to all these preparation methods is a high degree of microstructural disorder, which is correlated to porosity at elevated temperatures.

Generally, porosity in thermoelements is undesirable. While some researchers predict an enhancement to thermoelectric properties when a fine geometrically-controlled array of nanopores are used [14], in practice, porosity is commonly found to be deleterious. This has been demonstrated for $\mathrm{Bi}_{2} \mathrm{Te}_{3}$ [15], as well as other thermoelectric materials [16-19], i.e. pores generally scatter electrons more strongly than phonons. To prevent excessive porosity in thermoelements made from sintered nanocrystalline powders, pressure is generally applied during the consolidation stage [16]. However pores can still evolve within hot-pressed thermoelements when employed in a device, due to the relatively high temperatures experienced at the hot-side of the thermoelements. As-well as inhibiting thermoelectric properties, porous solids are less mechanically robust than fully dense ones [20], which, combined with shape changes and induced mechanical stresses, can lead to cracking and eventual device failure.

Despite many reports of thermally-induced porosity in $\mathrm{Bi}_{2} \mathrm{Te}_{3}$ and its solid solutions [5$7,10,13]$, to our knowledge no systematic or mechanistic studies of the foaming process have been made. The objective of this work is therefore to study the high temperature evolution of porosity in a nanocrystalline $\mathrm{Bi}_{2} \mathrm{Te}_{3}$ alloy that has been processed by mechanical alloying. In previous work we reported details of the compound formation process [21] and subsequent grain structure evolution [22] of the intermetallic during mechanical alloying of elemental powders. Here we report the porosity evolution of bulk nanocrystalline samples of $\mathrm{Bi}_{2} \mathrm{Te}_{3}$ after the powders have been consolidated by cold-pressing. The kinetics of porosity-induced 
sample expansion are measured up to $550{ }^{\circ} \mathrm{C}$ using a dilatometer. By combining these measurements with detailed microscopy and X-ray diffraction, pore formation is related to non-equilibrium phase separation, caused by the defect structure in the nanostructured compound. The resulting quantitative understanding makes it possible to predict the evolved porosity as a function of time and temperature, and thus provide safe operating bounds for service life of TEGs and other thermoelectric devices containing bismuth telluride. The mechanistic understanding also suggests palliative strategies for improved materials design.

\section{Experimental methods}

\subsection{Compact processing}

Nanocrystalline $\mathrm{Bi}_{2} \mathrm{Te}_{3}$ powders were fabricated by mechanical alloying of elemental powders Bi and Te (of nominal purity 99.5\%) inside a SPEX 8000 shaker mill. The milling device was operated at $1060 \mathrm{rpm}$ inside a glove box under a high-purity argon atmosphere. Stainless steel milling tools were employed at a ball-to-powder ratio of 5:1 for 4 hours of milling. Further details of the milling procedure and structural characterization can be found elsewhere [22]. Fig. 1(a) shows a transmission electron microscopy image (taken using a JEOL 2010 high resolution transmission electron microscope in bright field imagine mode) of the powders after mechanical alloying, indicating an average grain size of about $30 \mathrm{~nm}$. Powder compacts were made by cold pressing approximately $0.75 \mathrm{~g}$ of resulting powders in a uniaxial die press, operated inside the glove box. Compacts were compressed in a tool steel die of $6 \mathrm{~mm}$ bore diameter, under a pressure of $750 \pm 20 \mathrm{MPa}$, to a relative density $R D=\rho / \rho^{*}$ $=0.905 \pm 0.005$, where $\rho^{*}$ is the specific gravity of $\mathrm{Bi}_{2} \mathrm{Te}_{3}$, taken to be $7.86 \mathrm{~g} / \mathrm{cc}$ [23]. Fig. 1(b) shows a scanning electron microscopy image (taken using a JSM-6610 SEM in secondary electron imaging mode) of a compact cross-section, illustrating a high density in the as-pressed compact.

\subsection{Thermal analysis}

Differential scanning calorimetry (DSC) and thermogravimetric analysis (TGA) were performed on the as-pressed compacts using a Mettler Toledo DSC/TGA 1 operated with a purge gas of high purity argon. Thermomechanical analysis (TMA) was performed in a Netzsch 402 F3 dilatometer, with a purge gas mixture of $3 \% \mathrm{H}_{2}$ and remainder Ar. Each compact was heated under a low uniaxial stress $(900 \mathrm{~Pa})$ at a constant heating rate to the indicated set-point, followed by air cooling. The temperature was monitored using an S-type 
thermocouple, which was calibrated by the melting points of 6 metallic standards (In, Sn, Bi, $\mathrm{Pb}, \mathrm{Zn}$, and $\mathrm{Al}$ ). Thermal lag between sensor and sample was accounted for by repeating the calibration at various heating rates [24]. Expansion normal to the compact-press loading direction was slightly greater than in the radial direction in all samples, therefore, volumetric expansion was inferred from length changes measured by TMA under an assumption that the aspect ratio changed linearly with density. Finally, to calculate the instantaneous porosity, thermal expansion of both instrument and sample was corrected for. Instrumental expansion was corrected for using using an $\mathrm{Al}_{2} \mathrm{O}_{3}$ reference sample of known thermal expansion, while sample expansion was modelled using a constant thermal expansion coefficient for $\mathrm{Bi}_{2} \mathrm{Te}_{3}$, taken to be $17 \times 10^{-6} / \mathrm{K}[25]$.

\subsection{Characterisation}

To characterise any materials that were off-gassed during thermal analysis, the crucible was topped with a lid made from a single crystal wafer of silicon, which was oriented to yield near zero-background in X-Ray Diffraction (XRD). XRD was performed on the lid and on thermally treated compacts in a PANalytical X'Pert powder diffractometer operated with a $\mathrm{Cu}$ source at $40 \mathrm{kV}$ and $40 \mathrm{~mA}$. Patterns were collected at a scan rate of $2^{\circ} / \mathrm{min}$. The compact density was determined using a digital micrometer and microbalance, with respective accuracies of $\pm 5 \mu \mathrm{m}$ and $\pm 10 \mu \mathrm{g}$. Resulting porosity readings were validated using metallographic examination, by preparing cross sections using SiC paper of grit 12004000 followed by polishing with colloidal silica suspension $(0.05 \mu \mathrm{m})$. A measure of the pore volume fraction was made using the linear intercept method. In this method, straight lines were drawn through optical micrographs of the compacts at regular spacing such that no single pore is intercepted by more than one line. The pore volume fraction is taken as the fraction of the total line length that is traversing pores.

\section{Phase analysis}

The foaming behavior of $\mathrm{Bi}_{2} \mathrm{Te}_{3}$ will be shown in what follows as governed principally by the microstructure of the sample, and hence a preliminary discussion of the expected phases and how they differ in the case of mechanically milled samples - is crucial for interpretation of our results. As a first point to facilitate later understanding of non-equilibrium alloys, we consider samples made by solidification from a stoichiometric melt. According to the equilibrium phase diagram [26], the first material to crystallize is Bi-rich compared to 
nominal stoichiometry with a composition of about 40.065 at $\% \mathrm{Bi}$, due to a tendency for the compound to form $\mathrm{Bi}_{\mathrm{Te}}$ antisite defects [27]. As a result the material will be intrinsically ptype. However if Te-rich samples are made by forming an over-pressure the sample will be ntype due to $\mathrm{Te}_{\mathrm{Bi}}$ antisites.

In mechanically milled $\mathrm{Bi}_{2} \mathrm{Te}_{3}$, however, the equilibrium phase diagram does not apply; materials prepared at stoichiometric compositions phase separate despite being nominally within the single-phase region of the line-compound. This phenomenon can be explained as follows: During severe plastic deformation an excess of point defects in the form of anti-sites are produced. When material is subsequently annealed, these defects react to produce an excess of Tellurium vacancies, as proposed by Navratil and co-workers [28]:

$$
2 V_{B i}^{\prime}+3 V_{T e}^{o}+B i_{T e}^{\prime} \rightarrow V_{B i}^{\prime}+B i_{B i}^{x}+4 V_{T e}^{o}+3 e^{\prime}
$$

The excess $V_{T e}^{o}$ results in strongly n-type behavior [29] even in p-type alloy chemistries. This concept can be visualized in the schematic vertical line drawn Fig. 2(a), where the $\mathrm{Bi}_{2} \mathrm{Te}_{3}$ line compound is shifted to the Te-rich side. What this defect reaction means is that in the deformed state, the forced line compound is effectively supersaturated with Te and is shifted into the two-phase region, resulting in precipitation of a Te-rich phase during annealing. As a result, when $\mathrm{Bi}_{2} \mathrm{Te}_{3}$-based compounds are prepared via $\mathrm{MA}$, usually a strong Te-rich eutectic phase signature is observed in a DSC trace [30-32]. Indeed we observe the same eutectic melting peak in the DSC here, which is shown in Fig. 2(c). The DSC signal shows an exothermic transition beginning at about $410{ }^{\circ} \mathrm{C}$, corresponding to the eutectic phase transformation $\left(\mathrm{Te}+\mathrm{Bi}_{2} \mathrm{Te}_{3} \rightarrow \mathrm{L}\right.$ ) at $413{ }^{\circ} \mathrm{C}$ [33]. The total heat release is $2.1 \pm 0.5 \mathrm{~J} / \mathrm{g}$, which is equivalent to $3 \%$ of Te in the Te-rich phase, and $97 \%$ in the $\mathrm{Bi}_{2} \mathrm{Te}_{3}$-rich phase (based on an enthalpy of fusion for Te of $17.4 \mathrm{~kJ} / \mathrm{mol}$ [34]). Observations of precipitates of the Te-rich phase below the eutectic temperature are shown in the TEM micrographs of Fig. 2(a) and (d), which were taken of samples held isothermally for 2 hours at 330 and $400{ }^{\circ} \mathrm{C}$ respectively. The size of precipitates increases with increasing annealing temperature due to coarsening. 


\section{Pore evolution kinetics}

Fig. 3(a) illustrates the evolution in various thermal analysis signatures on nominally identical compacts that are heated to $550^{\circ} \mathrm{C}$ at a rate of $3{ }^{\circ} \mathrm{C} / \mathrm{min}$. The upper panel shows the average porosity, labelled $P$ and calculated as $P=1-R D$. The onset of significant porosity formation occurs at approximately $350{ }^{\circ} \mathrm{C}$, which is followed by a sharp transient to a peak rate of porosity evolution at approximately $408{ }^{\circ} \mathrm{C}$. Upon further heating, $P$ increases at a markedly slower rate toward a final porosity $P_{f}=0.51$. The measurement of $P_{f}$ from TMA is supported by manual density measurement and optical stereology, which yield values of $P_{f}=0.48$ and 0.52 respectively. Differences between the dimensionally-based and stereologically-based values could result from changes in bulk material density during phase separation. Although the density of $\mathrm{Bi}_{2} \mathrm{Te}_{3}$ is fairly insensitive to composition [23], the formation of Te-rich precipitates will decrease the density of the bulk by about $0.2 \%$ for every 1 vol. \% Te phase, since the density of Te is about $20 \%$ lower than that of $\mathrm{Bi}_{2} \mathrm{Te}_{3}$. Fortunately such effects are very small compared with the large porosity changes of most interest in this work.

The peak in pore growth rate at $408{ }^{\circ} \mathrm{C}$ is well matched to two characteristic processes shown by the signatures in the lower panel: (i) the eutectic melting process, as shown in by the peak in exothermic heatflow at $413{ }^{\circ} \mathrm{C}$; and (ii) the onset of sample mass loss, as shown by the downward signal in TGA mass change, beginning at approximately $400{ }^{\circ} \mathrm{C}$, resulting in a cumulative mass change of about $1 \%$.

The material that is lost from the sample is identified as tellurium vapor in Fig. 3(b), which shows background-corrected XRD patterns taken from the crucible lid after compacts were heated to $400{ }^{\circ} \mathrm{C}$ and $450{ }^{\circ} \mathrm{C}$. The patterns show that immediately below the eutectic point, i.e. at $400{ }^{\circ} \mathrm{C}$, the crucible is clean, while immediately above it at $450{ }^{\circ} \mathrm{C}$ some tellurium is deposited: The pattern is well matched to PDF 96-101-1099 for hexagonal tellurium, showing some preferential orientation normal to the basal plane - as indicated by the high intensity for the basal (003) peak and low intensity for the prism (010 and 110) peaks. This mass loss solely from evaporation of Te has been detected by other authors after sintering of $(\mathrm{BiSb})_{2} \mathrm{Te}_{3}$ [7] and is consistent with the fact that the vapor pressure of Te is approximately $10^{3}$ times that of $\mathrm{Bi}$ at these temperatures [35].

Fig. 4 shows TMA curves at various heating rates, indicating that faster heating rates lead to lower final porosity at a given temperature. For example, the upper panel, which shows 
instantaneous porosity, reveals that at the eutectic temperature: $P=0.29,0.27,0.23$, and 0.21 for samples heated at $1,3,10$, and $20^{\circ} \mathrm{C} / \mathrm{min}$ respectively. This rate affect is not simply a measurement artefact, as after cooling these samples from the maximum annealing temperature of $500{ }^{\circ} \mathrm{C}$, their macroscopic porosities were found to vary in a consistent manner: $P=0.40,0.40,0.38$, and 0.37 respectively.

Looking more closely at the upper panel in Fig. 4, the onset of porosity increase clearly occurs at different temperatures, while the overall rate maximum seems to occur always at the same temperature - close to the eutectic temperature of $413{ }^{\circ} \mathrm{C}$. The exact temperature of these events is visualized more clearly in the lower panel of Fig. 4, which shows the rate of change in porosity, $(\mathrm{d} P / \mathrm{d} t)$, normalized by the heating rate. The two peaks in $(\mathrm{d} P / \mathrm{d} t)$ correspond firstly to the onset of foaming - hereafter referred to as the "onset-peak" - and secondly to the maximum at the eutectic temperature - hereafter referred to as the "eutecticpeak". The derivative curve clearly shows that the onset-peak temperature ranges between about $350{ }^{\circ} \mathrm{C}$ and $395^{\circ} \mathrm{C}$, whereas the eutectic-peak occurs isothermally at a temperature slightly below the eutectic, at about $408^{\circ} \mathrm{C}$.

The effective activation energy for the foaming process corresponding to the onset-peak can be extracted using a Kissinger analysis [36]:

$$
\beta / T_{c}^{2}=\exp \left(Q / R T_{c}\right)
$$

where $\beta$ and $T_{c}$ are the heating rate and temperature of the peak respectively, $Q$ is the apparent activation energy controlling the kinetic process, and $R$ is the gas constant. Fig. 5 plots $\beta / T_{c}{ }^{2}$ against $1 / T_{c}$ for both the onset-peak and eutectic-peak temperatures extracted from Fig. 4. The line of best fit reveals an activation energy of $270 \pm 8 \mathrm{~kJ} / \mathrm{mol}$ for the process corresponding to the onset-peak, which is close to the activation energy for diffusionally

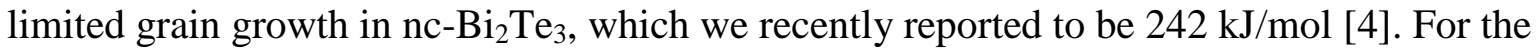
eutectic peak, no measureable temperature dependence was observed, confirming that some thermodynamic transition is occurring (i.e., melting point), which is not limited by any kinetic process.

To investigate the role of Te content, compacts were prepared in the range 58 at. $\%$ Te to 62 at. $\%$ Te. The resulting porosity evolution at a heating rate of $3{ }^{\circ} \mathrm{C} / \mathrm{min}$ is reported in Fig. 6 . Te-poor samples (58 and 59) display resistance to porosity up to $500{ }^{\circ} \mathrm{C}$. By contrast the Terich samples (61, and 62) show enhanced pore formation, reaching final porosities of 0.55 and 0.62 at $550{ }^{\circ} \mathrm{C}$, as compared to 0.48 at stoichiometric compositions. Like the 
stoichiometric material, these Te-rich samples show the same characteristic peak in foaming rate at the eutectic temperature.

\section{Pore structure}

The evolution in pore structure for stoichiometric samples is depicted in Fig. 7, by optical micrographs taken after heating compacts at $3^{\circ} \mathrm{C} / \mathrm{min}$ to various temperatures. The final porosities for compacts annealed at $400,450,500$, and $550{ }^{\circ} \mathrm{C}$ are $P=0.26,0.32,0.40$, and 0.48 respectively - as measured by macroscopic density measurements. These density measurements agree with stereoscopically measured porosities to within \pm 0.05 porosity. Initially, i.e. from $400{ }^{\circ} \mathrm{C}$, a mixture of isolated micro-scale and larger pores grow, with the largest pores measuring approximately $50-100 \mu \mathrm{m}$ in diameter. At higher temperatures, i.e. from $450{ }^{\circ} \mathrm{C}$ onwards, pores begin to impinge upon one another, and the images in Fig. 7 suggest coalescence into larger connected structures.

To further clarify the pore structure, Fig. 8 shows an optical micrograph (a) of the $550{ }^{\circ} \mathrm{C}$ compact cross section shown in Fig. 7, alongside an SEM micrograph (b) taken of a small section of the same region at higher magnification. Due to the much greater depth of view in the SEM, the structure of the pore wall can be seen. A hierarchical morphology is revealed where each pore is comprised of many smaller ones.

Pores nucleate primarily on precipitates, as shown by the TEM micrograph in Fig. 9 of a compact annealed at $400{ }^{\circ} \mathrm{C}$ for 2 hours, with a final porosity of $P=0.29$. The micrograph shows that all the pores present are abutted by precipitates - seen as regions of light and dark contrast respectively.

\section{Discussion}

A quantitative analysis of the kinetics of porosity evolution is difficult for two reasons. Firstly, the lack of high quality diffusion and creep data for $\mathrm{Bi}_{2} \mathrm{Te}_{3}-$ which are usually required for modelling pore growth - presents a challenge. Secondly, due to the highly non- 
equilibrium nature of the starting material, recovery, grain growth, phase separation, and eutectic melting occur simultaneously during annealing, making it difficult to separate their effects from one another and to compare experimental data to theory. Therefore in the following discussion, we employ only a semi-quantitative analysis in considering the relative importance of specific phenomena.

\subsection{Driving force:}

Foaming of $\mathrm{Bi}_{2} \mathrm{Te}_{3}$ is broadly driven via decomposition of the intermetallic into $\mathrm{Bi}_{2} \mathrm{Te}_{3}$ and a Te-rich eutectic at high temperatures. Evidence for this decomposition process is given in Fig. 2, via calorimetry, TEM, and diffraction data. Figs. 3-5 show that the peak foaming rate coincides with the eutectic transformation. Furthermore, the fact that sub-stoichiometric samples, e.g. with a Te content of 58 or $59 \%$ (and thus well within the $\mathrm{Bi}_{2} \mathrm{Te}_{3}+\mathrm{BiTe}$ phase field), do not exhibit a peak in foaming at the eutectic point, as shown in Fig. 6, confirms the role of the Te-rich phase in driving porosity.

However an explicit understanding of the origins of stress that forces deformation around a growing pore, remain unclear. For a pore to grow, the stress must exceed the interfacial stress that results from the increase in surface area. A simple force balance gives the required internal pressure to prevent the pore from sintering:

$$
P=\frac{2 \gamma}{r}
$$

where $r$ is the pore radius and $\gamma$ is the surface energy. For Te, $\gamma=0.36 \mathrm{~J} / \mathrm{m}^{2}$ [37], and from Fig. 4 the approximate pore radius is $50 \mu \mathrm{m}$, which gives a required internal pore pressure of about $\mathrm{p}=10 \mathrm{kPa}$. While this estimate neglects the distribution of pore sizes, (i.e., some pores are much smaller as observed in the TEM image of Fig. 9) and while for such nanopores, Eq. 3 may not be valid [38], this approach should give a reasonable average for the present discussion purposes. In the following discussion we consider two possible origins of such stress: (i) the abnormally high vapor pressure of Te [39], and (ii) residual trapped gas coming out of solution.

\subsubsection{Tellurium vapor pressure}

Te has an abnormally large vapor pressure, and as such is known to cause bubble formation in $\mathrm{Bi}_{2} \mathrm{Te}_{3}$ that is solidified from the melt [40]. The vapor pressure of Te over the solid $\mathrm{Te}$ and 
$\mathrm{Bi}_{2} \mathrm{Te}_{3}$ has been measured by Brebrick using optical density measurements [39]. The equilibrium vapor pressure of Te over the liquid and the solid are the given by:

$$
P_{0}=k \exp \left(\frac{-E}{R T}\right)
$$

where for solid and liquid phases, $k=3.52 \times 10^{12}$ and $5.31 \times 10^{9} \mathrm{~Pa}$, and $E=153$ and 114 $\mathrm{kJ} / \mathrm{mol}$, respectively. Table 2 lists the predicted vapor pressure above liquid Te given by Eqs. 3 and 4.

The vapor pressures listed in Table 2 are relatively small compared to our estimation of internal pore pressure. For example, at the eutectic point where a maximum in foaming rate is observed, the vapor pressure above the liquid Te phase is $28.4 \mathrm{~Pa}$, which is about 2-3 orders of magnitude lower than our estimation from Eq. 3 of $10 \mathrm{kPa}$. However the values in Table 1 assume that precipitates of Te are infinitely large, when in fact during the beginnings of phase separation, the precipitate size will be very small, which will induce an increase in vapor pressure due to interface curvature. The non-equilibrium vapor pressure, $P_{0}{ }^{r}$ for a solid or liquid with radius of curvature, $r$, is given by the Kelvin equation [41]:

$$
P_{0}^{r}=P_{0} \cdot \exp \left(\frac{2 \gamma V_{m}}{R T r}\right)
$$

where $P_{0}$ is the vapor pressure over a flat surface, $\gamma$ is the surface energy, $V_{m}$ is the molar volume, $T$ is the temperature and $R$ is the molar gas constant. Using Eq. 5, we estimate that the vapor pressure adjacent a Te precipitate could reach our pore pressure estimate of $10 \mathrm{kPa}$ (Eq. 3), for a spherical precipitate diameter of about $1 \mathrm{~nm}$, at $500{ }^{\circ} \mathrm{C}$.

\subsubsection{Trapped gas}

Secondly we consider the possibility of expansion of trapped gas being incorporated into the powders during milling and subsequent cold-pressing. We do not consider this as the dominant driving force, particularly as flash evaporated films [10] are also reported to exhibit thermally induced porosity and do not involve such process operations. However, the expansion of trapped gas is a common method of solid-state foaming by annealing of compacts made via Hot Isostatic Pressing of powders in an overpressure of Argon [42]. Expansion of trapped gas has been shown to cause pore expansion in cryo-milled $\mathrm{Cu}$ powders [43], and trapped gas is well known to prevent full density from being reached in during the final stages of sintering operations. The possibility of incorporating trapped gas during mechanical alloying is unlikely due to the very low solubility of Argon in metals. However, it 
is feasible that a small amount of gas could be trapped between pressed particles during cold pressing. The quantity of gas can be estimated via the relative density of the as-pressed powders, which gives a porosity of $P=0.1$, which is relatively small compared to the $P=$ 0.48 that was achieved in the case of the sample annealed at $550{ }^{\circ} \mathrm{C}$.

To test the possibility of trapped gases being incorporated via the methods discussed above, two control experiments were performed. The first was to fabricate a compact in vacuum from mechanically alloyed powders, and the second was to compress a compact in Argon from commercially obtained coarse-grained $\mathrm{Bi}_{2} \mathrm{Te}_{3}$ powders ( -325 mesh, $99.99 \%$ purity) that were not mechanically alloyed. The behaviour of these compacts is compared in Fig. 10 to the curve taken from Fig. 3, i.e. at the same heating rate of $3^{\circ} \mathrm{C} / \mathrm{min}$. The compact pressed in vacuum approximately overlays with the compact pressed in Argon, to within experimental error, confirming that trapped Argon gas from the pressing procedure does not contribute considerably to porosity. Furthermore, the compact pressed from commercially obtained powders still exhibits extensive foaming, confirming that mechanical alloying does not trap any extensive quantity of gas (although the degree of porosity is markedly lower - most likely because of their lack of nanostructured defects, following our reasoning in Section 3). We thus conclude that as suggested earlier, vaporization of tellurium is the source of the gas pressure, and the nanoscale structure of tellurium precipitates precipitated out of equilibrium contributes substantially to the high vapor pressure level that drives foaming.

\subsection{Deformation mechanism:}

With the above understanding of the driving force for grain growth, we now turn to the deformation mechanisms that can accommodate pore growth. Based on the equilibrium pore size, the vapor pressure was estimated to be on the order of $10 \mathrm{kPa}$. This is equivalent to a shear modulus-normalized shear stress $\gamma / \mu$, of about $10^{-6}$, which is small compared to typical dislocation creep stresses. It is therefore unlikely that typical dislocation creep can accommodate the flow. It is therefore likely that $\mathrm{Bi}_{2} \mathrm{Te}_{3}$ deforms via diffusional creep. To estimate transport rates, the grain size at the eutectic point can be estimated by employing the grain growth equation for a sample heated at constant rate, $b$ [44]:

$$
d^{n}(t)=d^{n}(0)+k_{0} \exp \left(\frac{-Q}{R T}\right) \cdot\left(\frac{R T^{2}}{b Q}\right)
$$


where $d$ is the grain size and $\mathrm{n}=6.5, k_{0}=6.7 \times 10^{-31} \mathrm{~nm}^{2} / \mathrm{s}$, and $Q=242 \mathrm{~kJ} / \mathrm{mol}$ are the grain growth exponent, kinetic constant and activation energy respectively that were measured recently in $\mathrm{nc}_{-} \mathrm{Bi}_{2} \mathrm{Te}_{3}[4]$. Despite the large shift in transient temperatures, the estimated grain sizes are nearly constant at 171, 168, 164 and $164 \mathrm{~nm}$ for heating rates of $1,3,10$, and $20^{\circ}$ $\mathrm{C} / \mathrm{min}$ respectively. This small grain size is consistent with a grain boundary transport regime being relevant for diffusional creep.

Grain boundary diffusion can be estimated on the basis of literature trends [45] according to the equation:

$$
\delta D_{G B}=D_{0} \exp \left(-B T_{m} / T\right)
$$

where $\delta$ is the grain boundary width which we assume to be $1 \mathrm{~nm}$, and $\mathrm{B}$ is a dimensionless grain boundary diffusion activation energy, $B=Q / R T_{m}$, which is on average between 10 and 15 for most materials [45] - and here we assume the average value of 12.5. Finally, $D_{0}$ is the attempt frequency which is between about $10^{-15}$ and $10^{-13} \mathrm{~s}^{-1}$ for most materials [45], which we take to be approximately $10^{-14} \mathrm{~s}^{-1}$. As a result, at the eutectic temperature, we estimate the grain boundary diffusivity to be on the order of $10^{-12} \mathrm{~m}^{2} / \mathrm{s}$.

This in turn allows us to estimate the Coble creep rate [46]:

$$
\dot{\varepsilon}_{S S}=\frac{42 \pi D_{G B} \sigma \delta \Omega}{k T d^{3}}
$$

where $\Omega$ is the atomic volume, $\sigma$ is the applied stress which we take to be the pore pressure, $p$ $=10 \mathrm{kPa}$, and $d$ is the grain size. Substituting for the estimated parameters: $D_{0}=10^{-12} \mathrm{~m}^{2} / \mathrm{s} ; T$ $=686 \mathrm{~K}$ (i.e. the eutectic point); and $d=170 \mathrm{~nm}$, yields a strain rate of $10^{-3} \mathrm{~s}^{-1}$. This is a rapid deformation rate for experiments taking place on the scale of hours; the peak strain rates observed on a global scale in the compacts are of order $10^{-5}-10^{-4} \mathrm{~s}^{-1}$. This analysis thus verifies that Coble creep is kinetically viable as a pore growth mechanism at the stress levels that we expect due to tellurium evaporation.

\subsection{Pore evolution kinetics:}

With an understanding of the likely deformation mechanism that accommodates the growing pore, we are now in a position to analyse the porosity evolution curves that were shown in Figs. 3 and 4. In particular, we note that the secondary transient, corresponding to the decrease in foaming rate that is observed at $408{ }^{\circ} \mathrm{C}$, is large and sudden; the rate falls by a factor of 2 in about 10-20 seconds regardless of the heating rate. This is about the same rate 
as is observed during discontinuous melting of pure metals and therefore likely to be limited by instrument response, and not the sample. We therefore view the shoulder in porosity evolution at $408{ }^{\circ} \mathrm{C}$ the result of an instantaneous change from the melting of Te-rich precipitates, since this temperature is very close to the eutectic temperature that was measured to be $410{ }^{\circ} \mathrm{C}$ by DSC in Fig. 3. We propose three possible reasons as to why the phase transformation could cause a large drop in the foaming rate:

1) Vapor pressure drop - During melting, Te liquid could wet the inside of growing pores, thus invoking a negative surface curvature which would immediately decrease the equilibrium vapor pressure in a discontinuous fashion.

2) Chemical redistribution - At the eutectic point, the Te-rich phase would begin to dissolve Bi from the matrix in order to follow the equilibrium solidus line. This would lower its vapor pressure.

3) Open porosity development - Since pores are located at Te precipitates, the melting of Te could open additional connections amongst pores, leading to more interconnected - and more importantly-more open, surface-connected porosity. The loss of vapor from the sample indeed begins at the eutectic temperature according to Fig. 3, just when the porosity becomes more connected according to our observations in Fig. 7. The loss of some Te vapor would lower the driving force for foaming.

\section{Conclusions}

We have shown that the foaming of nanocrystalline $\mathrm{Bi}_{2} \mathrm{Te}_{3}$ is driven by phase separation of the compound to form Te-rich precipitates, and the high vapor pressure above these precipitates. The compound decomposition is driven by the highly non-equilibrium nature of mechanically milled powders; the addition of excess defects and nanostructure moves the compound stoichiometry in such a way that the equilibrium compound composition is Terich, and precipitates Te upon heating. Pores that evolve subsequently are always adjacent to the terminal Te phase, and the pressure in them is due to Te evaporation. Although pore growth requires stresses of order $10 \mathrm{kPa}$, we show that this range of stresses is plausible given the vapor pressure above the solid Te and the very fine scale of the precipitates and the associated curvature effects on the vapor pressure. Our analysis also shows that the matrix deformation around a growing pore can be plausibly accommodated via diffusional creep 
over the timescales of our experiments. This in turn explains why finer initial nanostructures are expected to display enhanced foaming.

Despite the apparent ubiquity of porosity evolution in chalcogenide thermoelectric materials, the present work provides the only detailed study of the foaming process of which we are aware. The results offer some clear insights needed for the advancement of processing nanocrystalline thermoelectric materials, which are commonly fabricated via mechanical alloying or other non-equilibrium means. For example, our results suggest that in order to minimize foaming during powder consolidation, samples could be prepared at compositions that are slightly rich in the metallic species, i.e. in this case, $\mathrm{Bi}$. In addition, the mechanistic understanding developed suggests some materials design routes towards the mitigation of foaming. Traditional creep suppressers, such as second phase particles can inhibit high temperature creep and thus present an opportunity to engineer materials with higher dimensional stability. Although we have studied the effect of inert dispersoids on the stability of the grain structure in nanocrystalline tellurides [47], their effect on creep properties warrants detailed investigation in light of the present results.

While the results of this study are most pertinent to $\mathrm{Bi}_{2} \mathrm{Te}_{3}$ and its solid solutions, the observations have broader implications for the processing of other telluride compounds, and indeed chalcogenide semiconductor compounds such as the sulphides and selenides, which tend to form line compounds with similarly narrow phase fields, retrograde solubility, and high vapor pressure in the chalcogen-rich region of the phase diagram.

\section{Acknowledgements}

This material is based upon work supported as part of the Solid State Solar Thermal Energy Conversion (S3TEC) Center, an Energy Frontier Research Center funded by the U.S. Department of Energy, Office of Science, Office of Basic Energy Sciences under Award Number DE-SC0001299.

\section{References}

[1] Z.-G. Chen, G. Han, L. Yang, L. Cheng, J. Zou, Nanostructured thermoelectric materials: Current research and future challenge, Prog. Nat. Sci. Mater. Int. 22 (2012) 535-549. doi:10.1016/j.pnsc.2012.11.011. 
[2] W. Liu, X. Yan, G. Chen, Z. Ren, Recent advances in thermoelectric nanocomposites, Nano Energy. 1 (2012) 42-56. doi:10.1016/j.nanoen.2011.10.001.

[3] H. Alam, S. Ramakrishna, A review on the enhancement of figure of merit from bulk to nanothermoelectric materials, Nano Energy. 2 (2013) 190-212. doi:10.1016/j.nanoen.2012.10.005.

[4] S.A. Humphry-Baker, C.A. Schuh, Grain growth and structural relaxation of nanocrystalline Bi2Te3, J. Appl. Phys. 116 (2014) 153502. doi:10.1063/1.4898320.

[5] T. Kumpeerapun, H. Scherrer, J. Khedari, J. Hirunlabh, S. Weber, A. Dauscher, B. Lenoir, B. Zighmati, H. M'Jahed, V. Kosalathip, Performance of Low-Cost Thermoelectric Modules Fabricated from Hot Pressing and Cold Pressing Materials, in: 25th Int. Conf. Thermoelectr. 2006 ICT 06, 2006: pp. 136-140. doi:10.1109/ICT.2006.331299.

[6] M. Takashiri, S. Tanaka, H. Hagino, K. Miyazaki, Combined effect of nanoscale grain size and porosity on lattice thermal conductivity of bismuth-telluride-based bulk alloys, J. Appl. Phys. 112 (2012) 84315. doi:10.1063/1.4759326.

[7] O. Kim-Hak, M. Soulier, P.-D. Szkutnik, S. Saunier, J. Simon, D. Goeuriot, Microwave sintering and thermoelectric properties of p-type $\left(\mathrm{Bi}_{0.2} \mathrm{Sb}_{0.8}\right)_{2} \mathrm{Te}_{3}$ powder, Powder Technol. 226 (2012) 231-234. doi:10.1016/j.powtec.2012.04.051.

[8] M.A. Takashi Hamachiyo, Thermal Conductivity of $\mathrm{Bi}_{0.5} \mathrm{Sb}_{1.5} \mathrm{Te}_{3}$ Affected by Grain Size and Pores, J. Electron. Mater. 38 (n.d.). doi:10.1007/s11664-009-0718-2.

[9] J. Li, Q. Tan, J.-F. Li, Synthesis and property evaluation of $\mathrm{CuFeS}_{2-\mathrm{x}}$ as earth-abundant and environmentally-friendly thermoelectric materials, J. Alloys Compd. 551 (2013) 143-149.

[10]M. Takashiri, S. Tanaka, K. Miyazaki, Determination of the Origin of Crystal Orientation for Nanocrystalline Bismuth Telluride-Based Thin Films Prepared by Use of the Flash Evaporation Method, J. Electron. Mater. (n.d.) 1-9. doi:10.1007/s11664-013-2896-1.

[11]J.E. Ni, E.D. Case, R.D. Schmidt, C.-I. Wu, T.P. Hogan, R.M. Trejo, M.J. Kirkham, E. LaraCurzio, M.G. Kanatzidis, The thermal expansion coefficient as a key design parameter for thermoelectric materials and its relationship to processing-dependent bloating, J. Mater. Sci. 48 (2013) 6233-6244. doi:10.1007/s10853-013-7421-7.

[12]J.E. Ni, E.D. Case, R. Stewart, C.-I. Wu, T.P. Hogan, M.G. Kanatzidis, Bloating in $\left(\mathrm{Pb}_{0.95} \mathrm{Sn}_{0.05} \mathrm{Te}\right)_{0.92}(\mathrm{PbS})_{0.08}-0.055 \% \mathrm{PbI}_{2}$ Thermoelectric Specimens as a Result of Processing Conditions, J. Electron. Mater. 41 (2012) 1153-1158. doi:10.1007/s11664-011-1853-0.

[13]L.D. Zhao, B.-P. Zhang, W.S. Liu, H.L. Zhang, J.-F. Li, Effects of annealing on electrical properties of n-type $\mathrm{Bi}_{2} \mathrm{Te}_{3}$ fabricated by mechanical alloying and spark plasma sintering, $\mathrm{J}$. Alloys Compd. 467 (2009) 91-97.

[14]J.-H. Lee, J.C. Grossman, Thermoelectric properties of nanoporous Ge, Appl. Phys. Lett. 95 (2009) 13106. doi:10.1063/1.3159813.

[15]Z. Zhang, J.K. Yee, P.A. Sharma, N. Yang, E.J. Lavernia, Influence of porosity on the transport properties of $\mathrm{Bi}_{2} \mathrm{Te}_{3}$-based alloys by field-assisted sintering, J. Mater. Res. 28 (2013) 18531861. doi:10.1557/jmr.2013.99.

[16]S.K. Bux, J.-P. Fleurial, R.B. Kaner, Nanostructured materials for thermoelectric applications, Chem. Commun. 46 (2010) 8311-8324. doi:10.1039/C0CC02627A.

[17]H. Lee, D. Vashaee, D.Z. Wang, M.S. Dresselhaus, Z.F. Ren, G. Chen, Effects of nanoscale porosity on thermoelectric properties of SiGe, J. Appl. Phys. 107 (2010) 94308. doi:10.1063/1.3388076.

[18]D.J. Bergman, L.G. Fel, Enhancement of thermoelectric power factor in composite thermoelectrics, J. Appl. Phys. 85 (1999) 8205-8216. doi:doi:10.1063/1.370660.

[19]H. Lee, D. Vashaee, D.Z. Wang, M.S. Dresselhaus, Z.F. Ren, G. Chen, Effects of nanoscale porosity on thermoelectric properties of SiGe, J. Appl. Phys. 107 (2010) 94308. doi:10.1063/1.3388076. 
[20]L.J. Gibson, M.F. Ashby, Cellular solids: structure and properties, Cambridge University Press, 1999.

[21]S.A. Humphry-Baker, C.A. Schuh, The nanocrystalline thermoelectric compound Bi2Te3 forms by a particle-wise explosive reaction during mechanical alloying, Scr. Mater. 65 (2011) 516519. doi:10.1016/j.scriptamat.2011.06.014.

[22]S.A. Humphry-Baker, C.A. Schuh, Anomalous grain refinement trends during mechanical milling of $\mathrm{Bi}_{2} \mathrm{Te}_{3}$, Acta Mater. 75 (2014) 167-179. doi:10.1016/j.actamat.2014.04.032.

[23]G.R. Miller, C.-Y. Li, Evidence for the existence of antistructure defects in bismuth telluride by density measurements, J. Phys. Chem. Solids. 26 (1965) 173-177. doi:10.1016/00223697(65)90084-3.

[24]A.T. Riga, C.M. Neag, Materials Characterization by Thermomechanical Analysis, ASTM International, 1991.

[25]J.O. Barnes, J.A. Rayne, R.W. Ure Jr, Lattice expansion of Bi2Te3 from 4.2 K to 600 K, Phys. Lett. A. 46 (1974) 317-318. doi:10.1016/0375-9601(74)90243-6.

[26]C.B. Satterthwaite, R.W. Ure, Electrical and Thermal Properties of Bi2 Te3, Phys. Rev. 108 (1957) 1164-1170. doi:10.1103/PhysRev.108.1164.

[27]Scherrer, Scherrer, Thermoelectric Properties of BismuthAntimony Telluride Solid Solutions, in: D. Rowe (Ed.), Thermoelectr. Handb., CRC Press, 2005: pp. 27-1-27-19. http://www.crcnetbase.com/doi/abs/10.1201/9781420038903.ch27 (accessed January 12, 2012).

[28]J. Navrátil, Z. Starý, T. Plecháček, Thermoelectric properties of p-type antimony bismuth telluride alloys prepared by cold pressing, Mater. Res. Bull. 31 (1996) 1559-1566. doi:10.1016/S0025-5408(96)00149-3.

[29]J.M. Schultz, J.P. McHugh, W.A. Tiller, Effects of heavy deformation and annealing on the electrical properties of Bi2Te3, J. Appl. Phys. 33 (1962) 2443-2450. doi:10.1063/1.1728990.

[30] Hasezaki K, Nishimura M, Umata M, Tsukuda H, Araoka M, Mechanical Alloying of Bite and BiSbTe Thermoelectric-Materials, (n.d.)..

[31]S.S. Kim, S. Yamamoto, T. Aizawa, Thermoelectric properties of anisotropy-controlled p-type Bi-Te-Sb system via bulk mechanical alloying and shear extrusion, J. Alloys Compd. 375 (2004) 107-113. doi:10.1016/j.jallcom.2003.11.141.

[32]C.-W. Hwang, D.-B. Hyun, H.-P. Ha, T.S. Oh, Effects of excess Te on the thermoelectric properties of p-type $25 \% \mathrm{Bi}_{2} \mathrm{Te}_{3}-75 \% \mathrm{Sb}_{2} \mathrm{Te}_{3}$ single crystal and hot-pressed sinter, J. Mater. Sci. 36 (2001) 3291-3297. doi:10.1023/A:1017959008268.

[33]S. Chizhevskaya, L. Shelimova, V. Zemskov, V. Kosyakov, D. Malakhov, Expert Estimation and Matching of Data on the Phase-Diagram of the Bi-Te System, Inorg. Mater. 30 (1994) 1-8.

[34]Thermodynamic Properties of Elements, S7 to Ti, in: Pure Subst. Part 1 Elem. Compd. AgBr Ba3N2, Springer Berlin Heidelberg, 1999: pp. 101-124. http://link.springer.com/chapter/10.1007/10652891_8 (accessed May 5, 2014).

[35]-June 1 1972, American Institute of Physics Handbook, Third Edition, Mcgraw-Hill, New York, 1972.

[36]H.E. Kissinger, Reaction Kinetics in Differential Thermal Analysis, Anal. Chem. 29 (1957) 1702-1706. doi:10.1021/ac60131a045.

[37]D.A. Olsen, R.W. Moravec, A.J. Osteraas, Critical surface tension values of Group VIA elements, J. Phys. Chem. 71 (1967) 4464-4466. doi:10.1021/j100872a047.

[38]G. Nagayama, T. Tsuruta, P. Cheng, Molecular dynamics simulation on bubble formation in a nanochannel, Int. J. Heat Mass Transf. 49 (2006) 4437-4443. 
[39]R.F. Brebrick, Tellurium vapor pressure and optical density at 370-615.degree., J. Phys. Chem. 72 (1968) 1032-1036. doi:10.1021/j100849a043.

[40]A.L.U. Nguyen Thanh Nghi, Gaseous Bubble Formation in $\mathrm{Bi}_{2} \mathrm{Te}_{3}-\mathrm{Bi}_{2} \mathrm{Se}_{3}$ Melt, Cryst. Res. Technol. - Cryst Res Tech. 21 (1986) 367-374. doi:10.1002/crat.2170210309.

[41]H.-J. Butt, K. Graf, M. Kappl, Liquid Surfaces, in: Phys. Chem. Interfaces, Wiley-VCH Verlag GmbH \& Co. KGaA, 2003: pp. 4-25. http://onlinelibrary.wiley.com/doi/10.1002/3527602313.ch2/summary (accessed May 5, 2014).

[42]M.F. Ashby, A.G. Evans, N.A. Fleck, L.J. Gibson, J.W. Hutchinson, H.N.G. Wadley, Chapter 2 Making metal foams, in: M.F. Ashby, A.G. Evans, N.A. Fleck, L.J. Gibson, J.W. Hutchinson, H.N.G. Wadley (Eds.), Met. Foams, Butterworth-Heinemann, Burlington, 2000: pp. 6-23. http://www.sciencedirect.com/science/article/pii/B9780750672191500040 (accessed May 5, 2014).

[43]B.K. VanLeeuwen, K.A. Darling, C.C. Koch, R.O. Scattergood, Novel technique for the synthesis of ultra-fine porosity metal foam via the inclusion of condensed argon through cryogenic mechanical alloying, Mater. Sci. Eng. A. 528 (2011) 2192-2195. doi:10.1016/j.msea.2010.11.057.

[44]L.C. Chen, F. Spaepen, Analysis of calorimetric measurements of grain growth, J. Appl. Phys. 69 (1991) 679. doi:10.1063/1.347349.

[45]A.M. Brown, M.F. Ashby, Correlations for diffusion constants, Acta Metall. 28 (1980) 10851101. doi:10.1016/0001-6160(80)90092-9.

[46]A.S. Argon, Chapter 22 - Mechanical Properties of Single-Phase Crystalline Media: Deformation in the Presence of Diffusion, in: R.W. Cahn, P. Haasen (Eds.), Phys. Metall. Fourth Ed., NorthHolland, Oxford, 1996: pp. 1957-2007. http://www.sciencedirect.com/science/article/pii/B9780444898753500272 (accessed May 5, 2014).

[47]S.A. Humphry-Baker, C.A. Schuh, Suppression of grain growth in nanocrystalline Bi2Te3 through oxide particle dispersions, J. Appl. Phys. 116 (2014) 173505. doi:10.1063/1.4901235.

[48]Bi-Te Binary Phase Diagram 0-100 at.\% Te - SpringerMaterials, (n.d.). http://materials.springer.com/isp/phase-diagram/docs/c_0906501 (accessed May 20, 2016). 


\section{Captions}

Fig. 1. Mechanically alloyed $\mathrm{Bi}_{2} \mathrm{Te}_{3}$ observed by (a) transmission electron microscopy of the powders, showing nanocrystalline grain size of approximately $30 \mathrm{~nm}$, and (b) scanning electron microscopy, after cold-pressing of the powders into a pellet, showing a relative density of $R D=0.905$.

Fig. 2. (a) Phase diagram of the Bi-Te system [48], showing that at the stoichiometric 40Bi:60Te composition, single phase $\mathrm{Bi}_{2} \mathrm{Te}_{3}$ is predicted. To visualize the effect of plastic deformation-induced defects, a schematic line is drawn to the right that passes through the two-phase $\mathrm{Bi}_{2} \mathrm{Te}_{3}+\mathrm{Te}$ region. Evidence of such phase separation is presented in parts (b-e): part (b) shows a eutectic melting peak in DSC; part (c-d) show formation of precipitates, via TEM micrographs taken after annealing at 330, and $400{ }^{\circ} \mathrm{C}$ respectively for 2 hours; and part (e) shows that these precipitates can be identified as Te via the appearance of the Te (012) peak in XRD.

Fig. 3. (a) Porosity evolution (upper panel) at a heating rate of $3{ }^{\circ} \mathrm{C} / \mathrm{min}$ along with heatflow (lower panel) by differential scanning calorimetry and mass loss by thermogravimetric analysis. At the eutectic point, $\mathrm{Te}+\mathrm{Bi}_{2} \mathrm{Te}_{3} \rightarrow \mathrm{L}$, as shown by a peak in the heatflow signal, there is a corresponding slowing in the rate of porosity increase, while simultaneously the onset of mass loss begins. Mass loss above the eutectic is due to evaporation of Te gas, as shown in part (b), which shows XRD patterns indicating the appearance of hexagonal Te between $400^{\circ} \mathrm{C}$ and $450{ }^{\circ} \mathrm{C}$, on the crucible lid.

Fig. 4. Above: Porosity evolution curves for various heating rates between 1 and $20^{\circ} \mathrm{C} / \mathrm{min}$, showing increasing porosity with decreasing heating rate. Below: Derivative of the porosity curve showing a shift in the onset of porosity with heating rate, indicating that the porosity onset is controlled by diffusion. By contrast, the maximum in rate of porosity increase occurs isothermally at $410{ }^{\circ} \mathrm{C}$, which is close to the eutectic temperature of $410{ }^{\circ} \mathrm{C}$ (as measured by DSC).

Fig. 5. A Kissinger plot of the two peaks in foaming rate from Fig. 4, showing that the onset-peak has an activation energy of $270 \pm 8 \mathrm{~kJ} / \mathrm{mol}$, while the eutectic-peak occurs isothermally, at an average of $408^{\circ} \mathrm{C}$. 
Fig. 6. Porosity evolution at non-stoichiometric compositions. When the compound is forced to the Bi-rich compositions $(x=0.58,0.59)$, porosity formation is suppressed, due to the absence of Te-rich eutectic. At Te-rich compositions $(\mathrm{x}=0.61,0.62)$, porosity formation is further enhanced.

Fig. 7. Optical micrographs of cross-sections taken from compacts heated to various temperatures, showing the evolution in pore volume fraction and morphology. At $450{ }^{\circ} \mathrm{C}$ and above, pores coalesce into larger connected structures.

Fig. 8. An SEM image of a cross section of a compact heated to $550{ }^{\circ} \mathrm{C}$ reveals a hierarchical pore structure, where the large pores shown in Fig. 4 consist of many smaller pores that group together.

Fig. 9. A TEM image taken from a compact heated to $400{ }^{\circ} \mathrm{C}$ reveals tendency of pores to nucleate on precipitates.

Fig. 10. Porosity as a function of temperature for compacts pressed in vacuum, and from commercially obtained powders, compared to the conventional compact pressed in Argon. The vacuum-pressed sample overlays, confirming trapped gas plays no role. By comparison, the commercial compact exhibits lower levels of porosity. 


\section{Table 1}

Literature reports of thermally induced porosity for chalcogenide compounds.

\begin{tabular}{lllll}
\hline \hline Chemistry & Preparation method & Max porosity & $\begin{array}{l}\text { Max anneal } \\
\text { temp. }\left({ }^{\circ} \mathrm{C}\right)\end{array}$ & \begin{tabular}{l} 
Ref. \\
\hline $\mathrm{Bi}_{1.5} \mathrm{Sb}_{0.5} \mathrm{Te}_{3}$
\end{tabular} \\
$\mathrm{Bi}_{0.5} \mathrm{Sb}_{1.5} \mathrm{Te}_{3}$ & Crush and cold press & 0.11 & 500 & {$[5]$} \\
$\mathrm{Bi}_{2} \mathrm{Se}_{0.3} \mathrm{Te}_{2.7}$ & Sinter & 0.13 & 500 & \\
$\mathrm{Bi}_{0.4} \mathrm{Sb}_{1.6} \mathrm{Te}_{3}$ & Microwave sinter & 0.18 & 550 & {$[6]$} \\
$\mathrm{Bi}_{1.5} \mathrm{Sb}_{0.5} \mathrm{Te}_{3}$ & Mech. mill + hot press & 0.23 & 440 & {$[7]$} \\
$\mathrm{CuFeS}_{2}$ & Mech. alloy + spark plasma sinter & 0.11 & 500 & {$[8]$} \\
$\mathrm{Bi}_{2} \mathrm{Se}_{0.3} \mathrm{Te}_{2.7}$ & Flash-evaporate & Not reported & 350 & {$[9]$} \\
$\mathrm{PbTe}$ & Mech. mill + hot press & 0.22 & 450 & {$[10]$} \\
$\mathrm{Bi}_{2} \mathrm{Te}_{3}$ & Mech. alloy + spark plasma sinter & 0.15 & 320 & {$[13]$} \\
$\mathrm{Bi}_{2} \mathrm{~S}_{3}$ & Mech. mill + spark plasma sinter & 0.07 & 550 & {$[23]$}
\end{tabular}


Table 2

Vapor pressure above pure Te at various temperatures.

\begin{tabular}{cccc}
\hline \hline Event & Phase & Temperature $\left({ }^{\circ} \mathrm{C}\right)$ & $P_{0}(\mathrm{~Pa})$ \\
\hline \hline foaming onset $\left(1^{\circ} \mathrm{C} / \mathrm{min}\right)$ & solid & 351 & 0.6 \\
eutectic point & liquid & 413 & 8.5 \\
Te melting & liquid & 449 & 28.4 \\
$\mathrm{Bi}_{2} \mathrm{Te}_{3}$ melting & liquid & 585 & 618.0
\end{tabular}



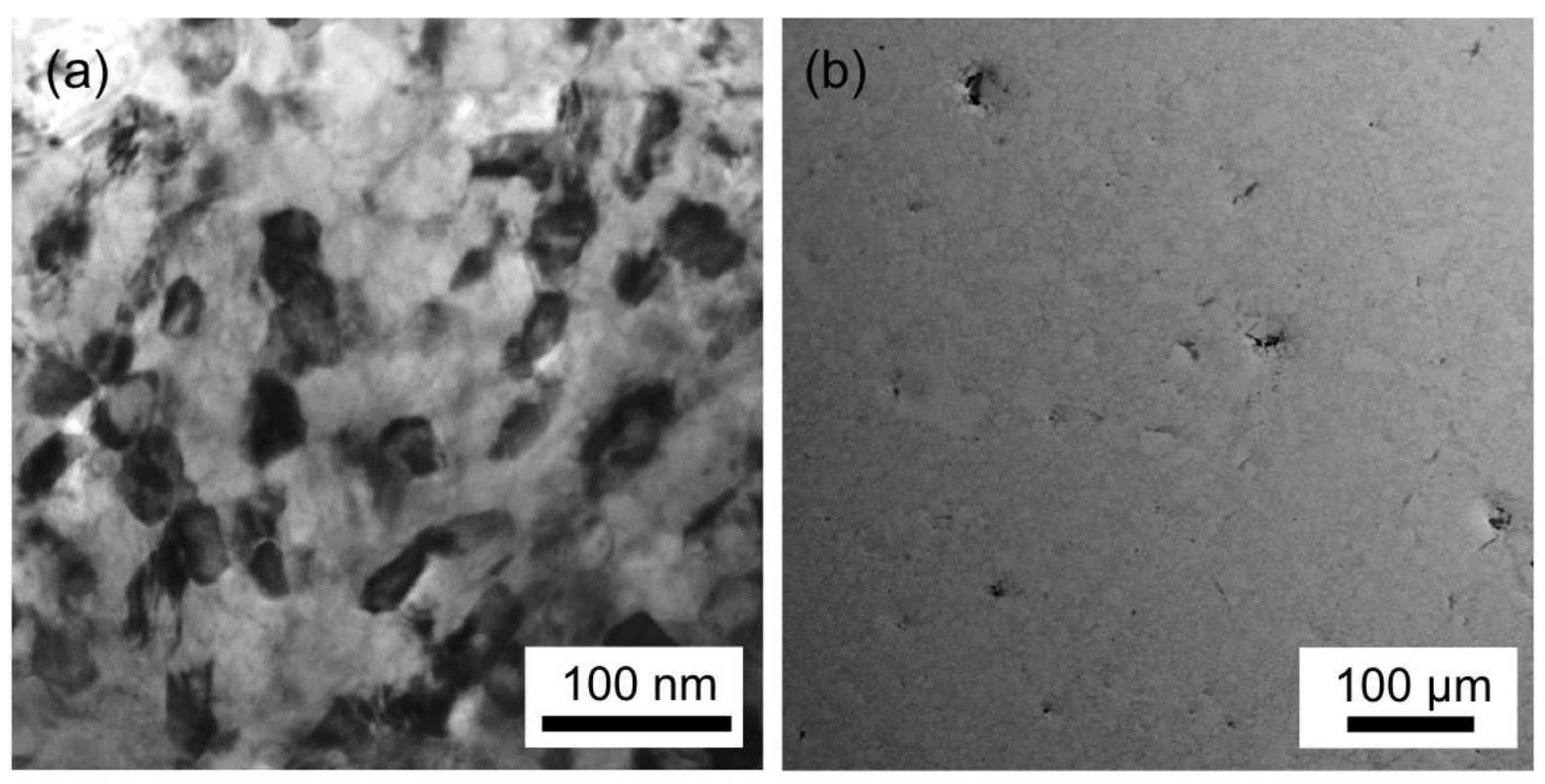

Fig. 1. Humphry-Baker \& Schuh 


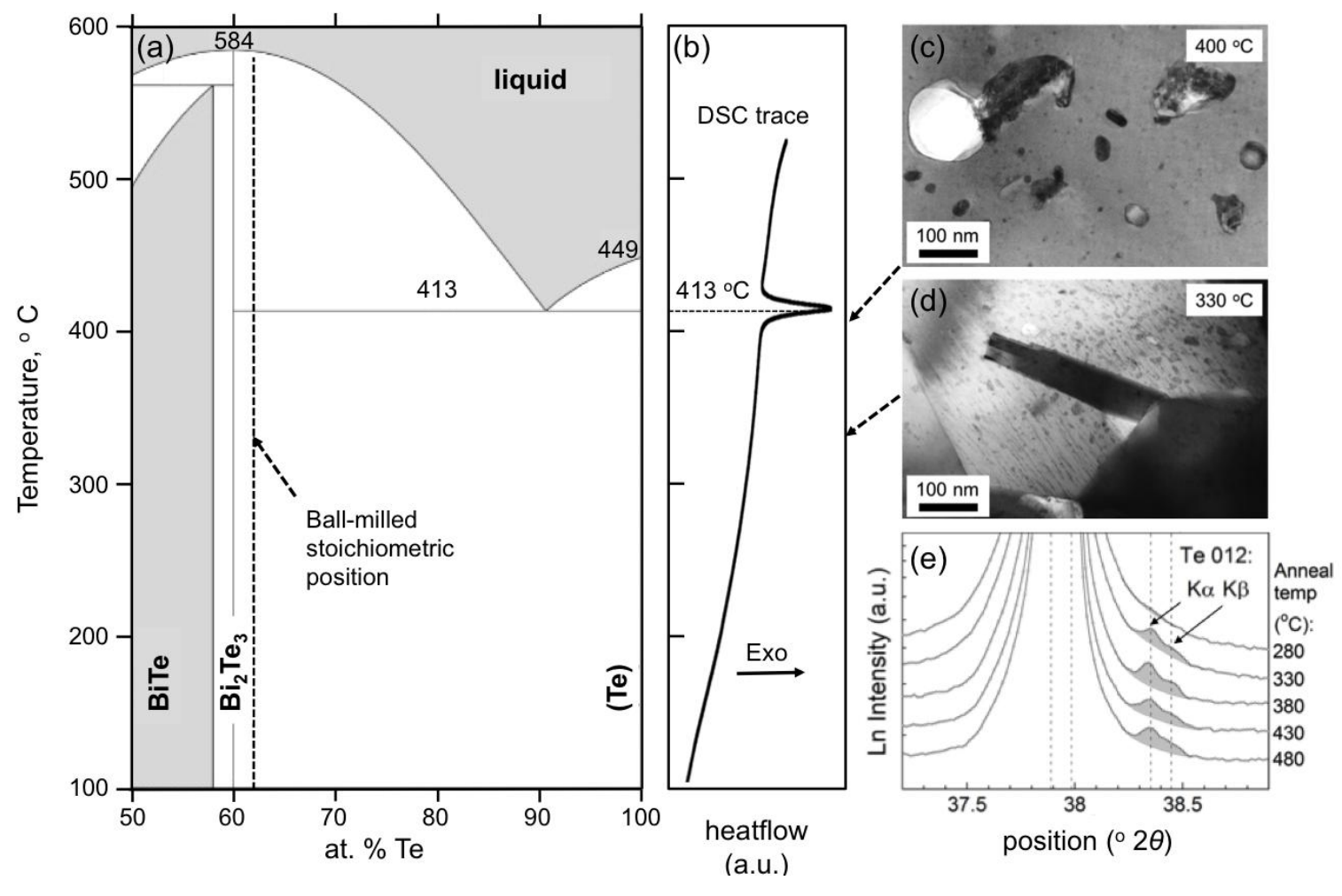

Fig. 2. Humphry-Baker \& Schuh 

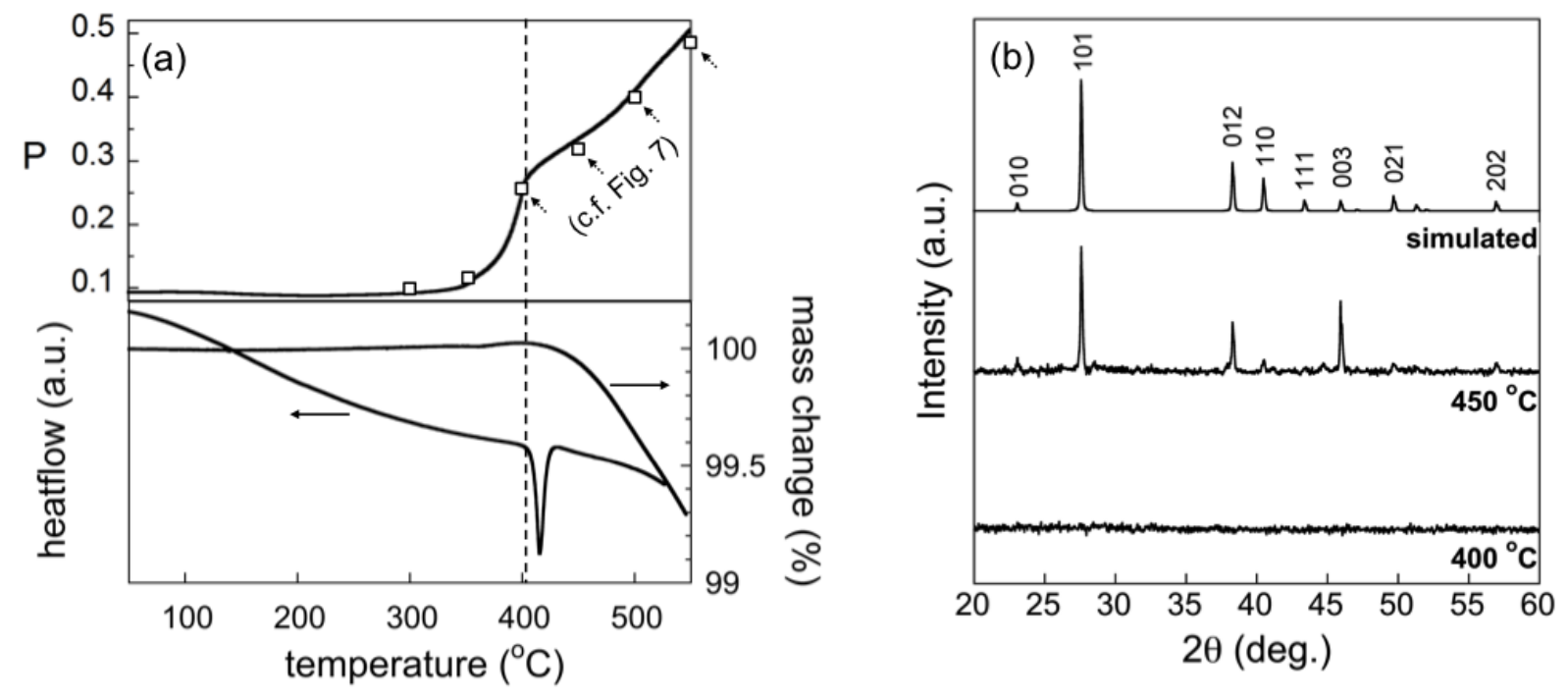

Fig. 3. Humphry-Baker \& Schuh 


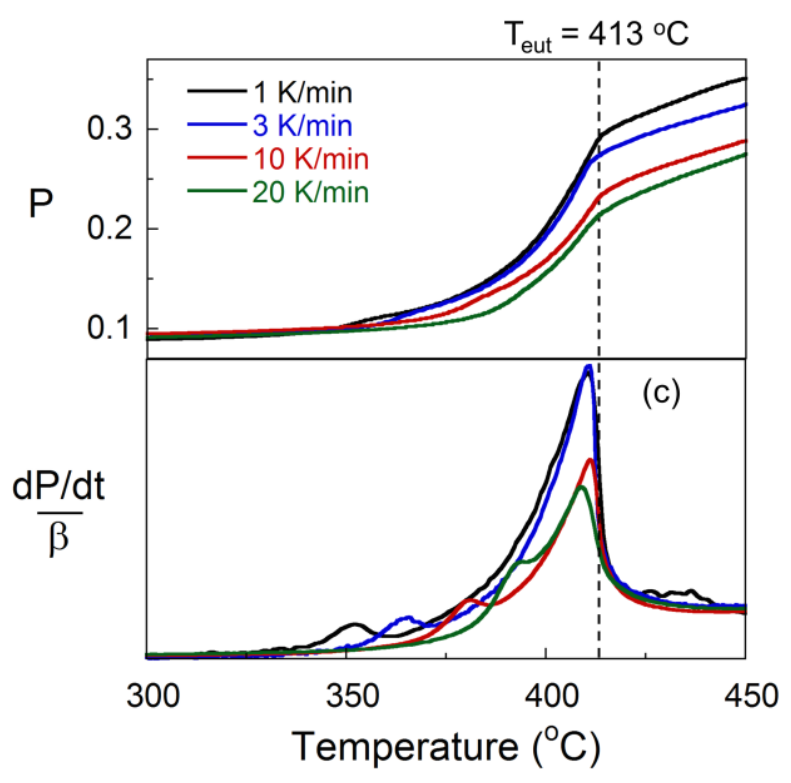

Fig. 4. Humphry-Baker \& Schuh 


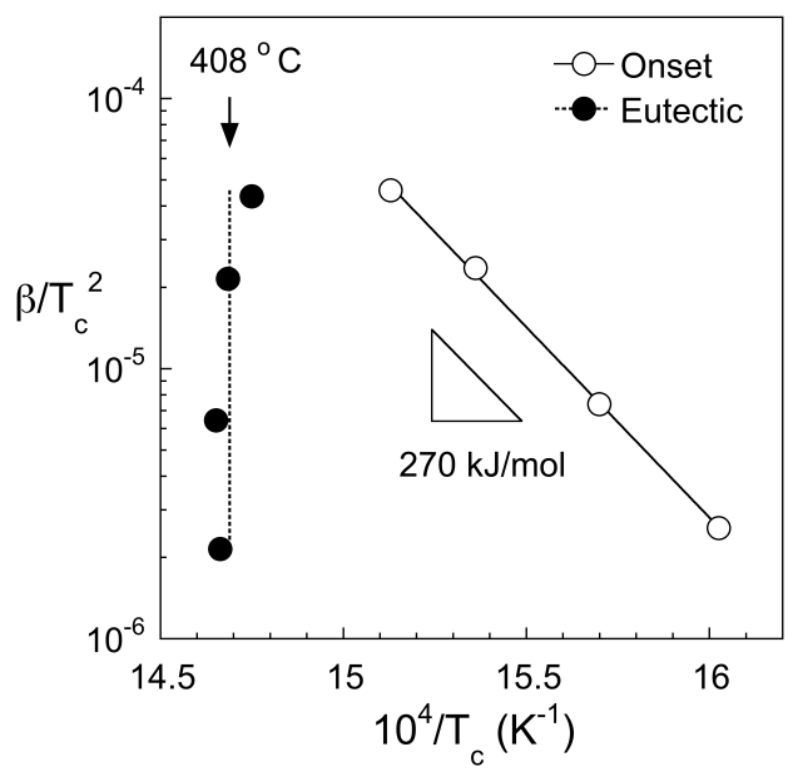

Fig. 5. Humphry-Baker \& Schuh 


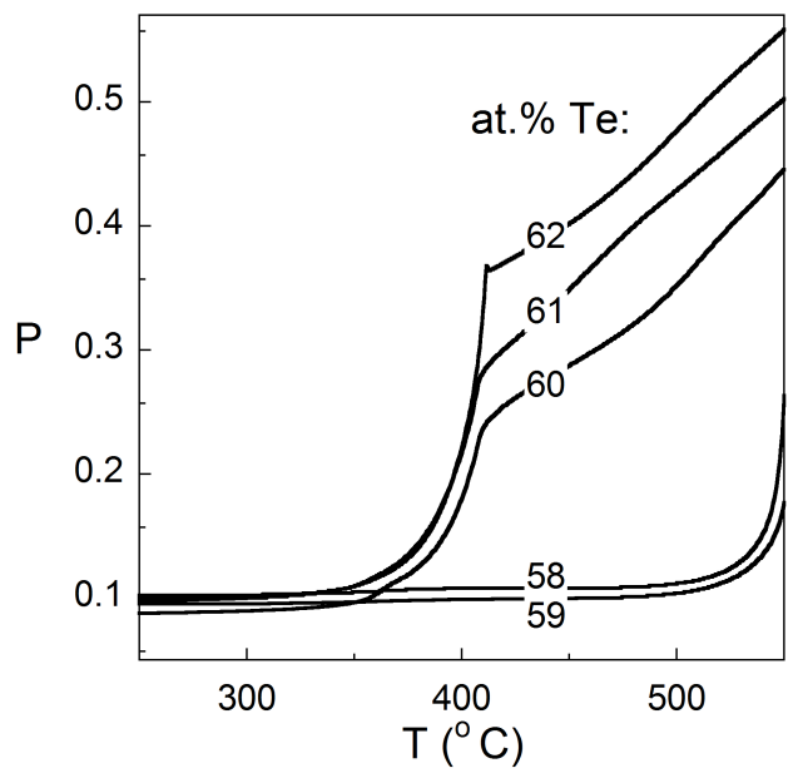

Fig. 6. Humphry-Baker \& Schuh 

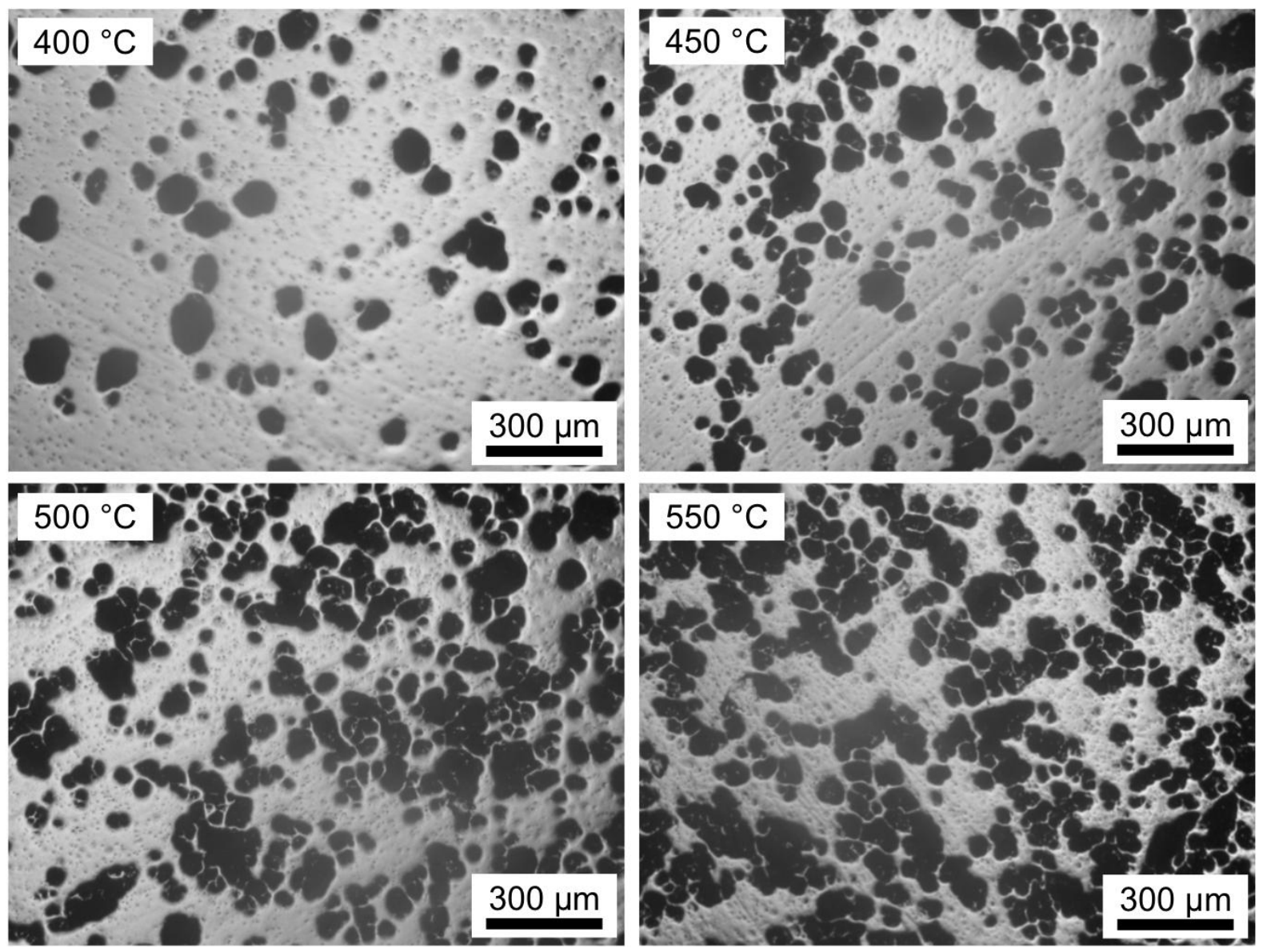

Fig. 7. Humphry-Baker \& Schuh 


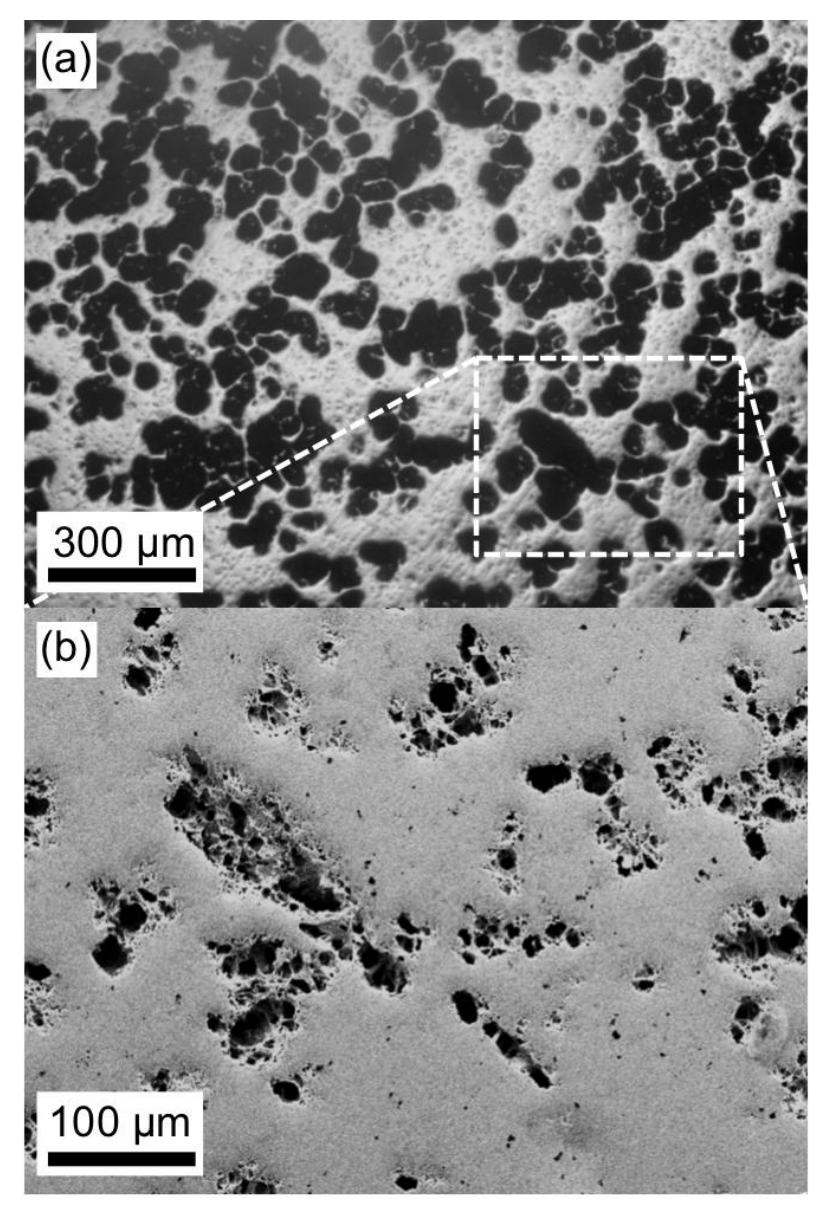

Fig. 8. Humphry-Baker \& Schuh 


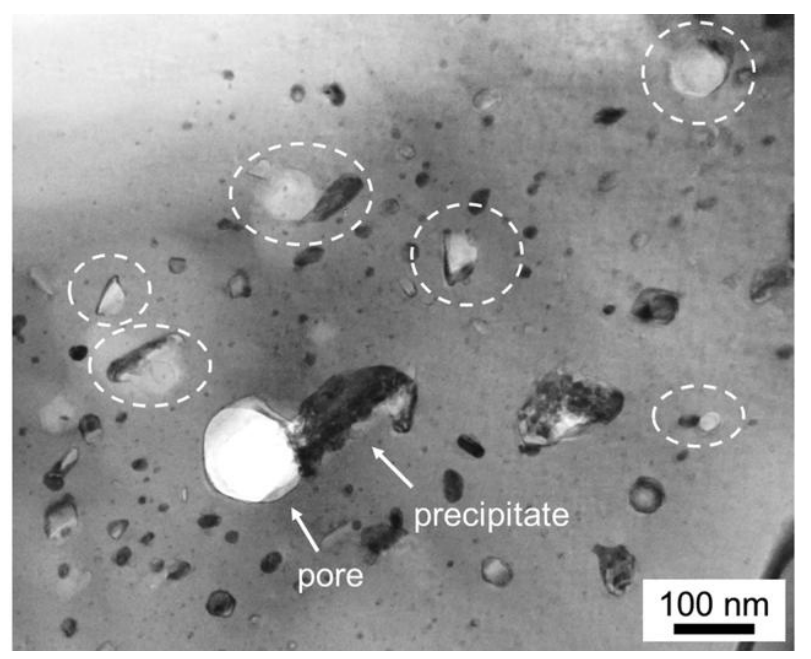

Fig. 9. Humphry-Baker \& Schuh 


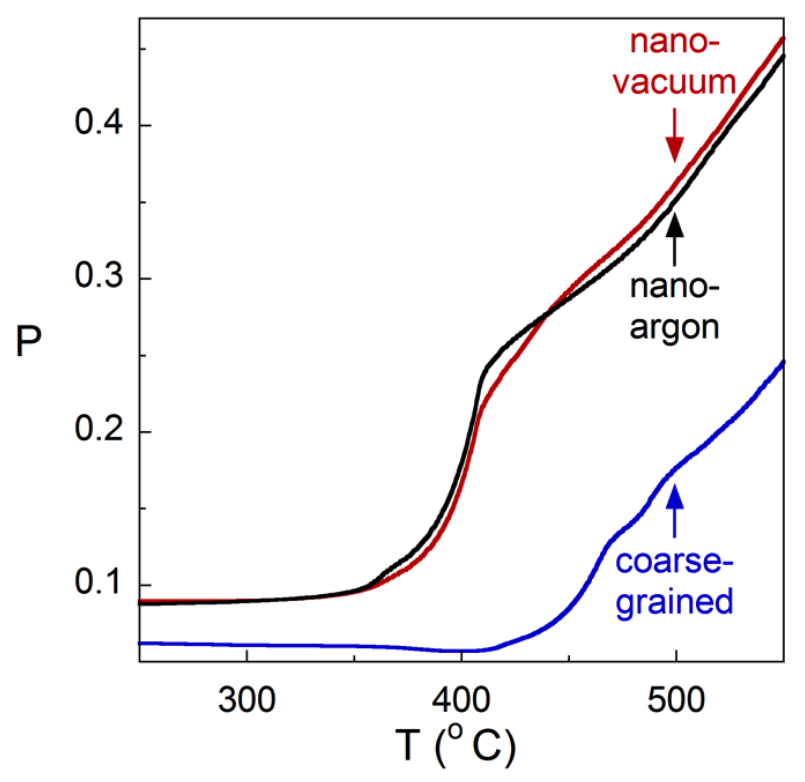

Fig. 10. Humphry-Baker \& Schuh 


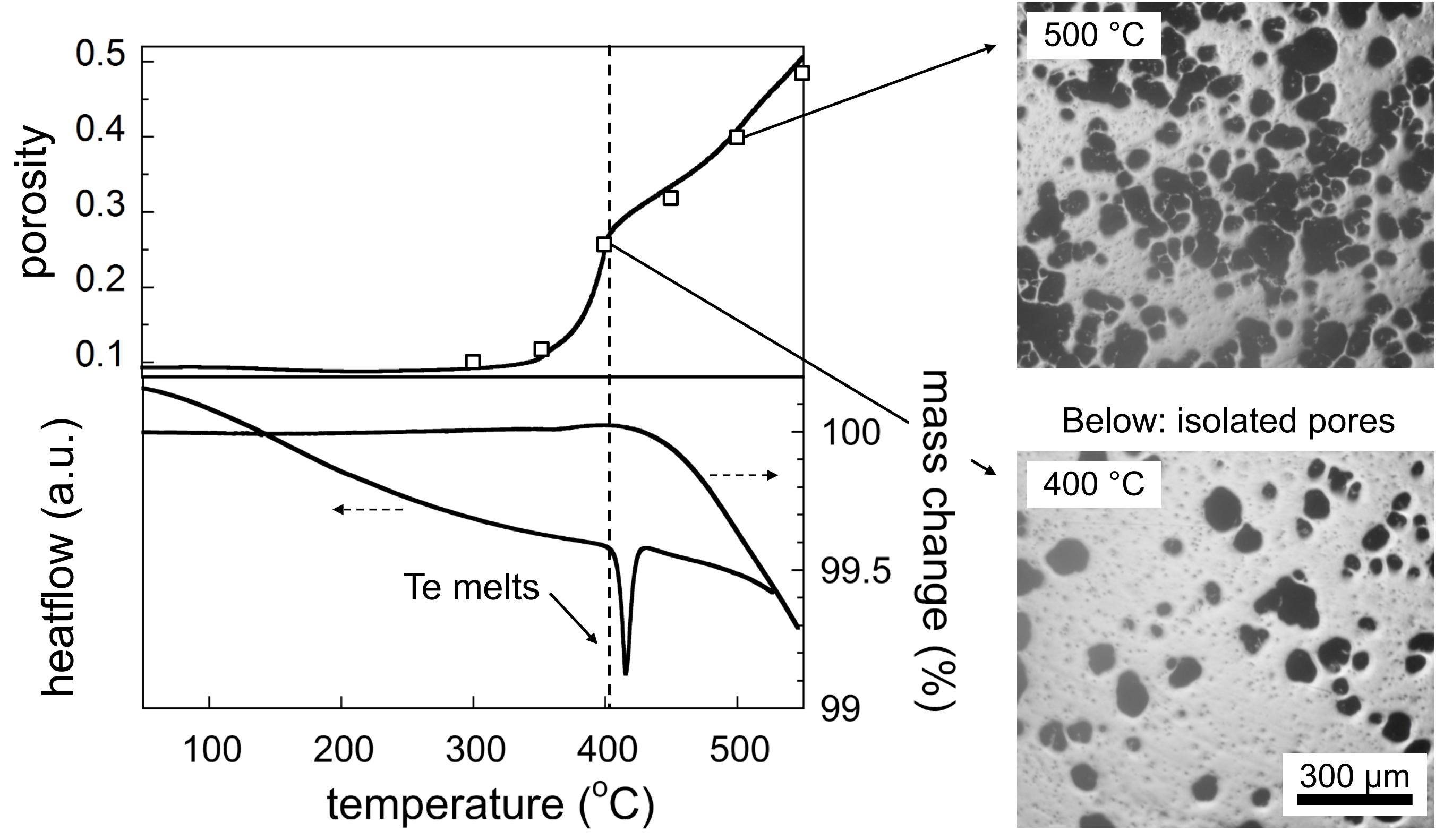

